\title{
CARACTERIZACIÓN PARCIAL DE DOS PROTEASAS DEL VENENO DE LA ARAÑA CASERA DEL PERÚ Loxosceles laeta
}

Frank Huari*; Fanny Lazo; Dan Vivas; Edith Rodríguez; Armando Yarlequé.

\section{RESUMEN}

A partir del veneno glandular de la araña casera Loxosceles laeta, se han aislado dos proteasas, una inespecífica con actividad sobre caseína y dimetilcaseína mientras que la otra es una proteasa con actividad procoagulante sobre plasma humano citratado. Para ello, se utilizó una columna de filtración molecular sobre Sephadex G-100, equilibrada con buffer acetato de amonio $0,05 \mathrm{M}$ pH 5,0, determinándose el contenido proteico por absorbancia a $280 \mathrm{~nm}$ y las respectivas actividades en cada fracción. También se midieron las actividades enzimáticas de: hialuronidasa, fosfolipasa $\mathrm{A}_{2}$, amidolítica, y la actividad hemorrágica. El análisis electroforético por PAGE-SDS determinó que la enzima proteolítica tiene un peso molecular de $35 \mathrm{kDa}$ en tanto que la fracción procoagulante registró un peso molecular de $15,9 \mathrm{kDa}$. La actividad proteolítica fue inhibida por EDTA $5 \mathrm{mM}$ en un $60,5 \%$ mientras que la fracción procoagulante fue inhibida por PMSF $5 \mathrm{mM}$ en un 93,3\%. Por tanto, tales enzimas corresponden a una metaloproteasa y a una serinoproteasa, respectivamente. Por ensayos de inmunodifusión doble, ambas proteínas mostraron reactividad inmunogénica frente al antiveneno loxoscélico comercial.

Palabras clave: Veneno, araña, proteasa, procoagulante, antiveneno.

\section{ISOLATION AND PARTIAL CHARACTERIZATION OF TWO PROTEASES FROM THE VENOM OF PERUVIAN Loxosceles laeta SPIDER}

\begin{abstract}
Two proteases from the glandular venom of Loxosceles laeta spider were isolated using a column of Sephadex G-100 gel molecular filtration equilibrated with 0,05M ammonium acetate buffer $\mathrm{pH} 5,0$. One of them is a metalloprotease inhibited by $5 \mathrm{mM}$ EDTA $(60,5 \%)$ and the other is a serinoprotease inhibited by $5 \mathrm{mM}$ PMSF $(93,3 \%)$. The metalloproteinase had activity on casein and dimethylcasein while the serinoprotease had activity on citrated human plasma. They showed different molecular weights by PAGE-SDS: $35 \mathrm{kDa}$ and

${ }^{*}$ Laboratorio de Biología Molecular-Facultad de Ciencias Biológicas, UNMSM. Av. Venezuela Cdra. 34 s/n. Lima 1.Perú. Teléfono: 6197000 Anexo 1528/1558. Email: ayarleque48@gmail.com
\end{abstract}


$15,9 \mathrm{kDa}$. In addition both were antigenic against commercial loxoscelic antivenom by immunodifusion assays.

Key words: Venom, spider, proteases, procoagulant, antivenom.

\section{INTRODUCCIÓN}

Las arañas del orden Araneae comprenden el grupo más diverso de la clase Arácnida con más de 39000 especies en el mundo. Dentro de ellas, los géneros Phoneutria, Atrax, Latrodectus y Loxosceles, los dos últimos cosmopolitas, representan un considerable problema de salud pública debido a los casos de envenenamiento por mordedura que infringen a los seres humanos, conocido en el campo clínico como Aracneísmo ${ }^{1}$. Sus venenos desencadenan un cuadro de alteraciones fisiológicas severas, ocasionado por la acción de distintos componentes, algunos de ellos, enzimas ${ }^{2,3}$.

En el Perú, los estudios acerca de la composición química del veneno de Loxosceles laeta, son escasos y se han centrado en al análisis del veneno total a partir de las glándulas venenosas o el obtenido por estimulación eléctrica ${ }^{2,4}$. Sin embargo, a juzgar por los efectos biológicos que el veneno genera, es necesario diferenciar los principales componentes que contiene.

La enzima más estudiada en el veneno del género Loxosceles es la esfingomielinasa $\mathrm{D}$, a la cual se le atribuye el efecto dermonecrótico, así como daño renal ${ }^{5}$. Sin embargo, la presencia y acción de enzimas proteolíticas no había sido abordada hasta la fecha.

En la presente investigación se han podido aislar dos componentes bioactivos con actividad proteolítica, los cuales pueden ser diferenciados por sus características bioquímicas, pero ambos son inmunogénicos frente al antiveneno loxoscélico. Se trata de una metaloproteasa y de una serinoproteasa.

\section{PARTE EXPERIMENTAL}

\section{Veneno}

Se obtuvo a partir del extracto glandular de la araña L. laeta. Las glándulas fueron extraídas de 250 ejemplares adultos hembras procedentes de Lurín y Pachacámac, Lima, resuspendidas en buffer acetato de amonio $0,05 \mathrm{M}$ pH 5,0 y luego de la centrifugación a $4000 \mathrm{rpm}$ el sobrenadante fue conservado a $-20^{\circ} \mathrm{C}$ hasta su uso.

\section{Determinación de la cantidad de proteína}

Fue realizada según el método de Lowry et al., (1951) modificado por Loayza et al., 1985. Para ello, se utilizó el reactivo de Folin Ciocalteus 1:6 y solución alcalina, midiendo la absorbancia a $660 \mathrm{~nm}$. Se usó albúmina sérica bovina como estándar. 


\section{Actividades enzimáticas:}

\subsection{Actividad proteolítica}

3.1.1 Se empleó el método de Takahashi y Ohsaka (1970), modificado por Rodríguez y Yarlequé $(1991)^{10}$. La mezcla de reacción contenía $1 \mathrm{~mL}$ de caseína al 1\% en buffer Tris-HCl 0,2 M pH 8,5;0,5 mL de agua destilada y $50 \mu \mathrm{L}$ del veneno total o fracción, incubándose a $37^{\circ} \mathrm{C}$ por $15 \mathrm{~min}$. Se midió la actividad a $280 \mathrm{~nm}$, luego de agregar ácido tricloro acético (TCA) 0,44 M en frío y obtener los centrifugados correspondientes. La actividad enzimática se determinó por la absorbancia a $280 \mathrm{~nm}$ de los productos ácido solubles y la actividad específica se expresó en unidades de actividad por mg de proteína.

3.1.2 Asimismo, se usó el método reportado por Lin et al., 1969, modificado por Sánchez et al., 2000 ${ }^{(11)}$; para lo cual se empleó $250 \mu \mathrm{L}$ de dimetilcaseína $0,2 \%$ y $250 \mu \mathrm{L}$ de buffer

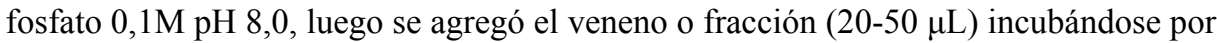
5 min a $37^{\circ} \mathrm{C}$. La reacción fue detenida por calentamiento a $100^{\circ} \mathrm{C}$ y posteriormente se adicionaron $250 \mu \mathrm{L}$ del reactivo TNBS $0,5 \%$ y $250 \mu \mathrm{L}$ de $\mathrm{NaHCO}_{3} 4 \% \mathrm{pH} 8,0$. Luego de 30 minutos a $50^{\circ} \mathrm{C}$ en oscuridad, se agregaron $250 \mu \mathrm{L}$ de SDS $10 \%$ y $125 \mu \mathrm{L}$ de $\mathrm{HCl}$ 1,0 N. Se midió la actividad a $340 \mathrm{~nm}$; este valor corresponde a las unidades de actividad enzimática, en tanto que la actividad específica se expresó en unidades por mg de proteína.

\subsection{Actividad procoagulante}

Se usó el método de medir el tiempo de recalcificación del plasma humano citratado, Yarlequé et al., (1986) ${ }^{9}$, al adicionarse $\mathrm{CaCl}_{2} 0,025 \mathrm{M}$. La mezcla de reacción contenía $0,2 \mathrm{~mL}$ de plasma humano citratado, $50 \mu \mathrm{L}$ de veneno total o fracción, incubándose por 5 min a $37^{\circ} \mathrm{C}$. El tiempo de recalcificación se midió en segundos, adicionando $0,1 \mathrm{~mL}$ de $\mathrm{CaCl} 2$ 0,025 M. La actividad enzimática fue determinada calculando las inversas de los tiempos de recalcificación del plasma humano citratado, considerando como $100 \%$ el tiempo normal de recalcificación y la actividad específica fue expresada en mg de proteína.

\subsection{Hialuronidasa}

Se evaluó por el método turbidimétrico de Di-Ferrante (1955), modificado por Hurtado et al., $2007^{8}$. La mezcla de reacción contenía $0,3 \mathrm{~mL}$ de buffer acetato de amonio $0,05 \mathrm{M}$ $\mathrm{NaCl} 0,15 \mathrm{M}, \mathrm{pH} 5,0$. Usando $0,1 \mathrm{~mL}$ de ácido hialurónico comercial $0,5 \mathrm{mg} / \mathrm{mL}$ diluido en el mismo buffer, se agregó $0,1 \mathrm{~mL}$ de veneno total o fracción de L. laeta y se incubó a $37^{\circ} \mathrm{C}$ por 15 minutos. La reacción fue detenida con $2 \mathrm{~mL}$ de Bromuro Cetil Trimetil Amonio (BCTA) 2,5\% en $\mathrm{NaOH} 2 \%$, midiéndose la absorbancia a $400 \mathrm{~nm}$.

La actividad enzimática se expresó en unidades Di-Ferrante, que corresponde a la reducción del 50\% de turbidez inicial del ácido hialurónico. La actividad específica fue expresada en Unidades Di Ferrante por mg de proteína. 


\subsection{Actividad amidolítica}

Fue determinada por el método de Erlanger et al., (1961) $)^{7}$ empleando el sustrato cromogénico Benzoil-Arginil-p-Nitroanilida (BApNA). La mezcla de reacción contenía 1,5 mL de BApNA 9x10 $0^{-4} \mathrm{M} ; 0,5 \mathrm{~mL}$ de buffer Tris-HCl 0,05 M pH 8,1 y $50 \mu \mathrm{L}$ del veneno total o fracción. Luego de incubar por 15 minutos a $37^{\circ} \mathrm{C}$ se adicionó $1 \mathrm{~mL}$ de ácido acético al $60 \%$ para medir la reacción a $405 \mathrm{~nm}$. La actividad específica fue expresada en $\mathrm{U} / \mathrm{mg}$, donde una unidad de actividad corresponde a los $\mu \mathrm{g}$ de $p$-nitroanilina liberados por minuto de reacción.

\subsection{Fosfolipasa $\mathrm{A}_{2}$}

Se exploró esta actividad usando el método espectrofotométrico de Oliveira y Palma, modificado por Lazo et al., $1998^{12}$. Usando fosfatidil colina $15 \mu$ moles a $\mathrm{pH} 7,9$ y midiéndose los cambios de absorbancia a $558 \mathrm{~nm}$ en presencia de rojo de fenol (80 nmoles).

\subsection{Actividad hemorrágica}

Se determinó midiendo el área hemorrágica producida por el veneno o fracción en piel de ratones albinos cepa Balb C usando el método de Kondo et al. (1960), modificado por Lomonte et al., 1982 ${ }^{13}$. La dosis hemorrágica mínima (DHM) es la cantidad de veneno capaz de inducir un área hemorrágica de $10 \mathrm{~mm}$ de diámetro.

\section{Fraccionamiento del veneno}

9,2 $\mathrm{mg}$ del extracto glandular fueron aplicados a una columna de Sephadex G-100 (32,5 x $0,58 \mathrm{~cm}$ ) equilibrada con buffer acetato de amonio $0,05 \mathrm{M} \mathrm{pH} \mathrm{5,0.} \mathrm{Se} \mathrm{colectaron} \mathrm{fracciones}$ de $1 \mathrm{~mL}$ y la cantidad de proteína fue medida en cada fracción a $280 \mathrm{~nm}$. Se ensayaron las actividades enzimáticas y la acción hemorrágica en cada fracción.

\section{Electroforesis en gel de poliacrilamida con dodecil-sulfato de sodio (PAGE-SDS)}

Se realizó según el método de Laemmli $(1970)^{14}$, tanto en condiciones reductoras y no reductoras, usando concentraciones de 10 y $12 \%$ de acrilamida en una cámara vertical Sigma, aplicando corriente eléctrica de 100 voltios. Los geles fueron teñidos con azul brillante de Coomassie al $0,1 \%$. Se usó como proteínas patrones: albúmina sérica bovina (66 kDa), ovoalbúmina (45 kDa) y lisozima $(14,3 \mathrm{kDa})$.

\section{Inhibidores proteolíticos}

Se ensayó el efecto del agente Etilendiamino tetra acético (EDTA) en el rango de 1,25 a $10 \mathrm{mM}$ y el Fenil metil sulfonil fluoruro (PMSF) en el rango de 1,25 a $6 \mathrm{mM}$. Para ello, se hicieron pre incubados de 5 minutos con las proteasas respectivas y luego se midieron las actividades enzimáticas.

\section{Antigenicidad de las enzimas en estudio}

La reactividad de las proteasas aisladas fue evaluada frente al antiveneno loxoscélico comercial (INS-Lima), mediante inmunodifusión doble (Ouchterlony \& Nilsson, 1967) ${ }^{15}$ en geles de agarosa al $1 \%$, incubados en cámara húmeda por 72 horas a $4^{\circ} \mathrm{C}$ y teñidos con azul brillante de Coomasie. 


\section{RESULTADOS}

Contenido de proteína en el veneno glandular.- En la tabla 1 se muestran los resultados obtenidos al cuantificar las muestras de veneno de cinco lotes de arañas. Se observa que la variación en el contenido proteico por araña está en un rango de 70 a $166 \mu \mathrm{g}$ de veneno.

Tabla 1. Contenido proteico de las extracciones glandulares de Loxosceles laeta

\begin{tabular}{lcccc}
\hline Lote & Número de arañas & \multicolumn{2}{c}{ Cantidad de proteína } & $\begin{array}{c}\text { Relación } \\
\text { ( } \begin{array}{c}\text { Pg veneno/araña) } \\
\text { Proteína total } \\
(\mathbf{m g})\end{array}\end{array}$ \\
\hline 1 & 20 & 2,1 & 2,09 & 104,5 \\
2 & 20 & 2,4 & 2,4 & 120 \\
3 & 60 & 3,98 & 9,96 & 166 \\
4 & 80 & 7,0 & 6,97 & 87,1 \\
5 & 116 & 6,76 & 8,12 & 70 \\
\hline
\end{tabular}

Actividades enzimáticas.- En la tabla 2 se muestran las actividades específicas de las proteínas en estudio presentes en el veneno total de $L$. laeta. No se detectaron las actividades de fosfolipasa $\mathrm{A}_{2}$, amidolítica ni acción hemorrágica.

Tabla 2. Actividades enzimáticas presentes en el veneno glandular de Loxosceles laeta

\begin{tabular}{lccc}
\hline Enzima & Substrato & $\begin{array}{c}\text { Actividad } \\
\text { Enzimática }\end{array}$ & $\begin{array}{c}\text { Actividad } \\
\text { Específica }\end{array}$ \\
\hline Hialuronidasa & Ácido hialurónico & 0,034 & 17,7 \\
Proteasa & Caseína & 0,061 & 7,2 \\
Proteasa & Dimetilcaseína & 0,341 & 0,57 \\
Pro.coagulante & Plasma humano & 0,012 & 0,625 \\
& citratado & & \\
\hline
\end{tabular}

Separación cromatográfica sobre Sephadex G-100.- El fraccionamiento del veneno de L. laeta $(9,2 \mathrm{mg})$ en este sistema, determinó la aparición de 3 picos proteicos. La actividad hialuronidasa fue detectada en la subida del segundo pico mientras que las actividades proteolítica y procoagulante se registraron en la subida y caída del tercer pico, respectivamente (figura 1, tabla 3). Tanto la fracción proteolítica como el veneno total no mostraron actividad hemorrágica. 


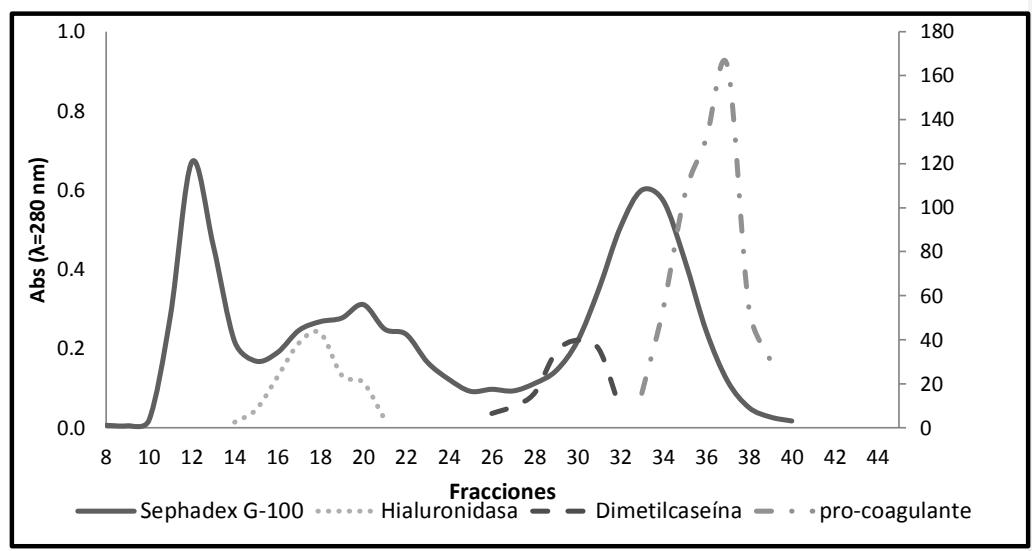

Figura 2. Perfil cromatográfico del veneno de Loxosceles laeta sobre Sephadex G-100 y ubicación de las actividades enzimáticas.

Peso Molecular.- Mediante PAGE-SDS, se determinó el patrón de bandas proteicas correspondientes tanto al veneno crudo, como a las enzimas en estudio; el veneno crudo presentó un total de 24 bandas proteicas en un rango de pesos moleculares de 15,9 a $97 \mathrm{kDa}$. La enzima con actividad proteolítica sobre dimetilcaseína se detectó como una única banda en condiciones reductoras y no reductoras, con un peso molecular de $35 \mathrm{kDa}$. En cuanto a la proteína procoagulante, su peso molecular fue de15,9 kDa, siendo la proteína más pequeña detectada en este veneno.

Tabla 3. Actividades enzimáticas detectadas en el veneno fraccionado en columna de Sephadex G-100

\begin{tabular}{lccccc}
\hline Enzima & $\begin{array}{c}\text { Proteína } \\
\text { total }\end{array}$ & $\begin{array}{c}\text { Actividad } \\
\text { específica }\end{array}$ & $\begin{array}{c}\text { Unidades } \\
\text { totales de } \\
\text { actividad }\end{array}$ & $\begin{array}{c}\text { Rendimiento } \\
\mathbf{( \% )}\end{array}$ & Purificación \\
\hline Hialuronidasa & 0,522 & 116 & 60,55 & 37,2 & 6,6 \\
Proteasa & 0,189 & 145 & 27,4 & 41,4 & 20,1 \\
Proteasa & 0,589 & 7,6 & 4,48 & 85,5 & 13,3 \\
Procoagulante & 1,077 & 133,7 & 144 & 87 & 7,4 \\
\hline
\end{tabular}

Inhibidores proteolíticos.- Al evaluar los efectos de agentes químicos sobre la actividad proteolítica y procoagulante, se encontró que el EDTA redujo considerablemente la actividad proteolítica sobre dimetilcaseína, hasta un 39,6\% (tabla 4) no teniendo efecto inhibitorio significativo el PMSF; contrariamente, este último agente inhibió hasta un 93,3\% la actividad procoagulante (tabla 4), mientras que el EDTA no tuvo efecto alguno. 
Inmunogenicidad.- En las pruebas de inmunodifusión doble, tanto el veneno crudo como la enzima proteolítica, fueron reconocidos por el antiveneno loxoscélico comercial, al formase bandas de precipitina y para el caso de la enzima procoagulante ocurre también la aparición de bandas de precipitina, pero de menor intensidad.

Tabla 4. Inhibición de las actividades proteolítica y procoagulante aisladas del veneno glandular de Loxosceles laeta.

\begin{tabular}{lccc}
\hline Agente & $\begin{array}{c}\text { Concentración } \\
(\mathbf{m M})\end{array}$ & \multicolumn{2}{c}{ Actividad enzimática (\%)) } \\
& Proteolítica & Procoagulante \\
\hline EDTA & ----- & 100 & 100 \\
& 1,25 & 60,6 & 98 \\
& 2,5 & 50 & 97 \\
& 5 & 39,5 & 99 \\
& 10 & 28,5 & 96 \\
PMSF & ------ & 100 & 100 \\
& 1,25 & 95,3 & 69,3 \\
& 2,5 & 100 & 6,7 \\
& 5 & 97 & 6,7 \\
& 10 & 96 & 5,4 \\
\hline
\end{tabular}

\section{DISCUSIÓN}

El limitante principal en el estudio del veneno de L. laeta, y en general del veneno de cualquier araña, es la cantidad de muestra que se obtiene de cada espécimen ${ }^{2,5}$, es decir algunos $\mu \mathrm{L}$. Esta es una gran diferencia con el veneno ofídico, en el cual se pueden obtener hasta $4 \mathrm{~mL}$ por ejemplar adulto. Este hecho obliga a la captura de un número considerable de arañas, para poder obtener una cantidad adecuada de veneno, especialmente de ejemplares hembras adultas que proporcionan una cantidad mayor de proteínas ${ }^{2}$. Es obvio que para obtener los extractos glandulares, sea para investigación o para producción del antiveneno loxoscélico, se deben sacrificar arañas, lo que a su vez puede generar en el tiempo una notable reducción de ellas en los lugares que habitan, ocasionando, por tanto, un incremento de insectos, ya que ellos son su alimento.

Como puede observarse en la tabla 1, las variaciones en el contenido proteico se deben a que los ejemplares usados tienen diferente grado de producción de la ponzoña, en función del ambiente, edad y del alimento.

Por otro lado, el fraccionamiento cromatográfico permitió identificar plenamente dos enzimas proteolíticas diferentes en este veneno, una metaloproteasa y una serinoproteasa. Estos grupos de enzimas están involucrados en la generación de los principales desórdenes locales y sistémicos producidos por envenenamiento de origen animal. Está demostrado 
que las metaloproteasas afectan tanto las proteínas tisulares como las plasmáticas, causando daños diversos, en tanto que las serinoproteasas actúan más directamente sobre las proteínas sanguíneas, como el fibrinógeno y los factores procoagulantes ${ }^{9}$.

Nuestros resultados evidencian que el veneno en estudio acelera el tiempo de coagulación del plasma humano (actividad procoagulante) y degrada sustratos como caseína y dimetilcaseína (actividad proteolítica); siendo este último el sustrato idóneo, debido a la menor cantidad de veneno requerido y de una mayor sensibilidad ${ }^{16}$ cercana a 10 veces con respecto a la caseína (tablas 2 y 3 ).

Los ensayos con los inhibidores proteolíticos demostraron que esta actividad disminuyó considerablemente con EDTA, agente quelante de iones divalentes, por lo que puede concluirse que dicho componente enzimático es una metaloproteasa.

Para el caso del género Loxosceles, y a diferencia de los venenos de origen ofídico, el ión $\mathrm{Zn}^{2+}$ podría estar presente en la estructura tridimensional de la proteasa, es así que varios reportes han clasificado a estas enzimas en el grupo similar a Astacina, que son proteasas multifuncionales que tienen un dominio ligando a dicho ión, estas metaloproteasas son encontradas en varios organismos, desde bacterias a mamíferos, interviniendo en procesos fisiológicos como digestión, degradación de proteínas extracelulares, morfogénesis, eclosión de embriones, fertilización, entre otras ${ }^{2}$.

En cuanto a la actividad procoagulante, esta se vio severamente afectada por el PMSF inhibidor específico de las proteasas que contienen serina en su sitio activo, este se une irreversiblemente al aminoácido serina de la cadena polipeptídica, por ello se ha determinado en este veneno la presencia de, al menos, una serinoproteasa. Esta enzima, también encontrada en otros arácnidos, tiene características similares a la que describen Devaraja et al., $2008^{17}$, quienes aislaron una proteasa de $16,3 \mathrm{kDa}$ de peso molecular, de naturaleza serinoproteica en la araña de embudo Hippasa agelenoides.

Asimismo, la ausencia de las actividades amidolítica y coagulante indican que L. laeta no tiene acción directa sobre el fibrinógeno, pero no se descarta una actividad fibrinogenolítica ${ }^{17}$, la cual es causada principalmente por serinoproteasas. Adicionalmente, la ausencia de la actividad fosfolipasa del tipo $\mathrm{A}_{2}$ no descarta la presencia de esta enzima, debido a que pueden ser enzimáticamente inactivas pero biológicamente activas, como en el caso de las esfingomielinasas tipo $\mathrm{D}^{5}$.

Por otro lado, el análisis cromatográfico permitió dilucidar que las actividades reportadas son realizadas por enzimas propias, al detectarse en fracciones marcadamente separadas y que estas se presentan en proporciones únicas con respecto al contenido proteico del veneno, no obstante, juntas estas fracciones, representan poco más del $30 \%$ del contenido proteico total; si bien es cierto que el concepto de que el agente principal en los venenos de arañas son las enzimas del grupo de las esfingomielinasas $\mathrm{D}^{5}$, este estudio permite inferir que las proteasas también tendrían un papel importante en el proceso de envenenamiento. 
Los análisis electroforéticos del veneno total mostraron un rango de peso molecular entre 15,9 a $97 \mathrm{kDa}$. Para el caso de la enzima proteolítica se registró un peso molecular de $35 \mathrm{kDa}$ y para la enzima procoagulante de $15,9 \mathrm{kDa}$. Veiga et al., $2000^{18}$ reportaron que, adicionalmente a la zona rica en proteínas de 5 a $40 \mathrm{kDa}$, había otra de 60 a $85 \mathrm{kDa}$ presentes en el veneno de este género, donde varios de los componentes mayores a $50 \mathrm{kDa}$ corresponderían a proteínas de naturaleza glandular.

Las enzimas estudiadas presentan estructura monocatenaria, ya que su migración electroforética no fue alterada por el agente reductor $\beta$-mercaptoetanol; así también, se deduce que son moléculas inmunogénicas, al originar líneas de precipitación con el antiveneno loxoscélico producido por el Instituto Nacional de Salud - Lima.

El presente estudio constituye el primer esfuerzo para detectar y caracterizar bioquímicamente la presencia de componentes diferentes a la esfingomielinasa D.

\section{CONCLUSIONES}

El veneno de la araña Loxosceles laeta contiene, por lo menos, dos proteasas, una del tipo metaloproteasa y la otra, serinoproteasa. La metaloproteasa tiene un peso de $35 \mathrm{kDa}$, en tanto que la serinoproteasa de 15,9 kDa. Ambas son cromatográficamente separables, unicatenarias $\mathrm{y}$ antigenicamente reactivas frente al antiveneno loxoscélico comercial.

\section{AGRADECIMIENTO}

Los autores agradecen al Vicerrectorado de Investigación de la UNMSM por el apoyo financiero otorgado a esta investigación. Uno de los autores (F. Huari) obtuvo su Título Profesional de Biólogo con mención en Zoología con parte de este estudio.

\section{REFERENCIAS BIBLIOGRÁFICAS}

1. Coddington JA. Phylogeny and classification of spiders. In: Ubick D, Paquin P, Cushing PE. and V. Roth, Editores. Spider of North America: an identification manual. Mitchell: American Arachnological Society; 2005 .p. 18-24.

2. Zavaleta A. Loxoscelismo, un problema de salud en el Perú. Bol Sanit Panam. 1987; 103(4):378-86.

3. Vetter RS. Spiders of the genus Loxosceles (Araneae, Sicariidae): a review of biological, medical and psychological aspects regarding envenomations. J Arachnology. 2008; 36:150-163.

4. Arbaiza E, Venegas J, Yarlequé A, Zavaleta A. Aportes al estudio de las acciones proteolíticas, procoagulantes y caracterización electroforética de las proteínas de dos extractos tóxicos del veneno de Loxosceles laeta. Bol Chil Parasitol; 1989; 44: 8-16

5. De Santi Ferrara G, Fernandes-Pedrosa F, Junqueira-de-Azevedo I, Gonçalves-de- 
Andrade R, Portaro F, Manzonide-Almeida D. SMase II; a new sphingomyelinase D from Loxosceles laeta venom gland: Molecular cloning, expression, function and structural analysis. Toxicon. 2009; 53: 743-753.

6. Loayza S, Morante Y, Campos S, Yarlequé A. Enzimas proteolíticas en el veneno de las serpientes peruanas Lachesis muta y Bothrops atrox. Bol Soc Quim Perú. 1985; 52(3): 151-163

7. Erlanger B, Kokowsky N, Ochemm W. The preparation and properties of two new chromogenic substrates of Tripsin. Arch Biochem Biophys. 1961; 95: 271-78.

8. Hurtado L, Lerma 1, Rodríguez E, Yarlequé A. Evaluación, aislamiento y algunas propiedades bioquímicas de una hialuronato glucanohidrolasa del veneno de la serpiente peruana Lachesis muta "Shushupe". Rev Soc Quim Perú. 2007; 73(4): 226-234

9. Yarlequé A, Heredia V, Arbaiza E, Zavaleta A. Estudios electroforéticos y acción procoagulante del veneno de Loxosceles laeta. Diagnóstico. 1986; 17(2):39-45.

10. Rodríguez E, Yarlequé A. Aislamiento y algunas propiedades de la Proteinasa I del veneno de la serpiente peruana Lachesis muta. Acta Cien Venez. 1991; 42 (4): 219-25.

11. Sánchez E, Santos C, Magalhaes A, Diniz C, Figueiredo S, Gilroy J. Isolation of proteinase with plasminogen-activating activity from Lachesis muta muta (Bushmaster) snake venom. Arch Biochem Biophys. 2000; 378 (1): 131- 141.

12. Lazo F, Rodríguez e, Yarlequé a: Evaluación comparative de dos métodos para determinar la actividad de Fosfolipasa A en venenos de serpientes. Rev Perú Biol. 1998; 5(2): 98-102.

13. Lomonte B, Cerdas L, Gene J, Gutiérrez JM. Neutralization of local effects of the terciopelo (Bothrops asper) venom by blood serum of the colubrid snake Clelia clelia. Toxicon. 1982; 20(3): 571-579.

14. Laemmli UK. Cleavage of structural proteins during the assembly of the head of bacteriophage T4. Nature. 1970; 227(5259): 680-85.

15. Ouchterlony O, Nilsson L. Inmunodifussion and inmunoelectrophoresis. Handbook of Experimental immunology. 1967; I (34): 655-60.

16. Sanchez E, Santos C, Magalhaes A, Diniz C, Figuereido S, Gilroy J. Isolation of proteinase with plasminogen-activating activity from Lachesis muta muta (Bushmaster) sanke venom. Arch Biochem Biophys. 2000; 378(1): 131-141.

17. Devaraja S, Nagaraju S, Mahadeswaraswamy YH, Girish KS, Kemparaju K. A low molecular weight serine-protease: purification and characterization from Hippasa agelenoides (funnel web) spider venom gland extract. Toxicon. 2008; 52:130-138.

18. Veiga S, da Silveira RB, Dreyfuss J, Haoach J, Pereira A, Mangili O, Gremski W. Identification of high molecular weight serine-proteases in Loxosceles intermedia (brown spider) venom. Toxicon. 2000; 38(6): 825-839. 